\title{
Development of a Clinical Functional Magnetic Resonance Imaging Service
}

\section{Citation}

Rigolo, Laura, Emily Stern, Pamela Deaver, Alexandra J. Golby, and Srinivasan Mukundan. 2011. "Development of a Clinical Functional Magnetic Resonance Imaging Service." Neurosurgery Clinics of North America 22 (2) (April): 307-314. doi:10.1016/j.nec.2011.01.001.

\section{Published Version}

doi:10.1016/j.nec.2011.01.001

\section{Permanent link}

http://nrs.harvard.edu/urn-3:HUL.InstRepos:34183144

\section{Terms of Use}

This article was downloaded from Harvard University's DASH repository, and is made available under the terms and conditions applicable to Other Posted Material, as set forth at http:// nrs.harvard.edu/urn-3:HUL.InstRepos:dash.current.terms-of-use\#LAA

\section{Share Your Story}

The Harvard community has made this article openly available.

Please share how this access benefits you. Submit a story.

\section{Accessibility}




\title{
Development of a Clinical Functional Magnetic Resonance Imaging Service
}

\author{
Laura Rigolo, MA, Emily Stern, MD, Pamela Deaver, MD, Alexandra J. Golby, MD, and \\ Srinivasan Mukundan Jr., PhD, MD
}

\begin{abstract}
One of the limitations of anatomical based imaging approaches is its relative inability to identify whether specific brain functions may be compromised by the location of brain lesions or contemplated brain surgeries. For this reason, methods for identifying the regions of eloquent brain that should not be disturbed are absolutely critical to the surgeon. By accurately identifying these regions preoperatively, virtually every pre-surgical decision from the surgical approach, operative goals (biopsy, sub-total vs. gross-total resection), and the potential need for awake craniotomy with intraoperative cortical-mapping is affected. Of the many techniques available to the surgeon, functional magnetic resonance imaging (fMRI) has become the primary modality of choice due to the ability of MRI to serve as a "one-stop shop" for assessing both anatomy and functionality of the brain. Given their prevalence, brain tumors serve as the model pathology for the included discussion; however, a similar case can be made for the use of fMRI in other neurological conditions, most notably epilepsy. The value of fMRI was validated in 2007 when the Centers for Medicare and Medicaid Services (CMS) established three new current procedural terminology (CPT) codes for clinical fMRI based upon its use for pre-therapeutic planning. In this article we will discuss the specific requirements for establishing an fMRI program, including specific software and hardware requirements. In addition, the nature of the fMRI CPT codes will be discussed.
\end{abstract}

\section{Background}

From the discovery of the Roentgen Ray over a century ago, the primary focus of radiology has been the non-invasive demonstration of structural anatomy of the human body. Through the demonstration of alteration of normal anatomy, the identification of pathology was elicited. The wide availability of cross sectional imaging modalities, first with computed tomography (CT) followed by magnetic resonance imaging (MRI), resulted in marked improvements in the quality of the depiction of anatomical structures in three-dimensional space. The anatomical region most impacted by these techniques was the neuraxis, which had been previously hidden by the calvarium and vertebral column.

As this issue of the Clinics demonstrates, a new focus on physiologic imaging has developed over the past two decades. Through these methods, the imaging aim has shifted from the demonstration of anatomy to the evaluation of physiology. Many of these so-called

\footnotetext{
(c) 2011 Elsevier Inc. All rights reserved.

Corresponding Author: Srinivasan Mukundan, Jr. PhD, MD, Section Head of Neuroradiology, Department of Radiology, Brigham and Women's Hospital, Associate Professor of Radiology, Harvard Medical School, smukundan @ partners.org.

Publisher's Disclaimer: This is a PDF file of an unedited manuscript that has been accepted for publication. As a service to our customers we are providing this early version of the manuscript. The manuscript will undergo copyediting, typesetting, and review of the resulting proof before it is published in its final citable form. Please note that during the production process errors may be discovered which could affect the content, and all legal disclaimers that apply to the journal pertain.
} 
"functional imaging" approaches are being refined, including the imaging of blood flow (perfusion), specific metabolites (spectroscopy) and regional blood oxygenation (Blood Oxygen Level Dependent, or BOLD imaging.) Taken as a whole, each of these methods can be considered functional imaging, although the aim of this article is to describe approaches involving BOLD imaging.

As more completely described elsewhere in this issue, BOLD imaging is based on a phenomenon first described by Roy and Sherrington in Cambridge in 1890 demonstrating that neural activation induced increased blood flow in the blood vessels supplying and draining that area of cerebral cortex (24). This phenomenon remained unexploited for nearly a century until the development of Positron Emission Tomography (PET) imaging in the 1980 's. The phenomenon was further leveraged with the development of BOLD functional magnetic resonance imaging (fMRI) in 1990 (19). The power of the BOLD method was made evident in early studies when regions of brain activation associated with various motor, sensory, visual and language tasks were mapped in normal subjects (12). This was followed by the development of paradigms used to evaluate pathologic states including brain tumors, multiple sclerosis, strokes, epilepsy and Alzheimer's disease.

The fMRI technique remained largely a research modality until 2007 when the Centers for Medicare and Medicaid Services (CMS) issued three separate current procedural terminology (CPT) codes for its clinical use (Table I). The recommendation for the development of CPT codes was based largely upon experience at major academic medical centers that had begun to use fMRI as a presurgical technique for mapping eloquent regions of the brain, typically under the auspices of an institutional review board (IRB) approved protocol. Using this approach, the typical study consisted of developing fMRI paradigms for the identification of motor areas, speech centers, and sensory regions that should be avoided by the surgeon during a craniotomy. This development of clinical CPT codes has led to significantly increased interest in the use of fMRI by clinicians and consequent increases in the number of studies ordered in many institutions. The aim of this short article is to describe both the rationale for establishing a clinical fMRI service and the basic requirements for hardware and software. In addition, there is a short discussion on the implementation of the CPT codes.

\section{Rationale for establishing an fMRI Center in support of Brain Tumor Centers}

According to the Brain Tumor Society, there are in excess of 200,000 newly diagnosed brain tumors (primary or metastatic) each year within the United States. Despite significant advances in both chemotherapy and radiation treatments, neurosurgery remains the preeminent treatment modality in most cases. Numerous outcomes of gross-total resection of a brain tumor include: relief of mass effect, decreased risk of epilepsy, increased time to tumor progression, and increased survival $(1,2,21)$. However, the pre-operative goal of gross total resection can be thwarted intraoperatively by the difficulty in determining tumor boundaries. This is particularly true for infiltrating gliomas which may be difficult to distinguish from healthy brain due to indistinct, infiltrative margins with healthy brain parenchyma. Moreover, the proximity of tumor to eloquent brain carries the risk of functional loss following surgery if those regions are violated. By mapping the boundaries of eloquent brain in the context of tumor-distorted anatomy, neurofunctional testing approaches have been used over the past quarter century to improve surgical outcomes. 


\section{Functional Imaging}

Functional MRI is a non-invasive MR-based brain mapping technique that requires no exogenous contrast agents. Through the investment in a minimal amount of hardware and software that can be obtained at incremental cost, fMRI can be added to most existing MR scanners. Evaluation of multiple functions is feasible in patients with cerebral tumors using fMRI (16), and pre-operative maps depicting brain areas activated during motor, sensory, and language tasks can be obtained using task paradigms specific to the function or functions of interest. Typical paradigms include motor mapping (e.g. hand clenching, finger tapping, toe movement), language (word generation, sentence completion and similar tasks) and visual stimulation (typically a flashing checkerboard or annulus). The resulting maps are useful for pre-surgical planning and can be integrated into neuronavigation systems to guide intra-operative decision-making $(6,7,10,11,13,14,17,18,22,23)$ (Figure 1). Strong evidence that a more radical tumor resection may be achieved by using fMRI information during neurosurgery has been demonstrated by Krishnan et al. (2004) and Haberg et al. (2004) $(8,11)$. Diffusion tensor imaging (DTI) based tractography has recently emerged as another potentially valuable tool to visualize white matter anatomy for pre-operative planning $(3,5,9,15,27-29)$ and postoperative follow-up (4) of surgically treated brain tumors and vascular malformations (Figure 2). In addition, the use of fMRI has been shown to significantly reduce operative time and facilitate pre-operative decision making as to whether to perform surgeries awake or under general anesthesia (20).

\section{Software and Hardware Requirements}

Although most mid- and high-field MRI scanners in clinical use are capable of performing functional magnetic resonance imaging, most will require upgrades of scanner software and hardware to perform the imaging. In addition, software "keys" for specialized pulse sequences required for performing fMRI on the MRI scanner, such as BOLD or diffusion tensor imaging (DTI) echo planar sequences, may be required. Specialized software is required both for administering the test and for interpreting the test results properly. These will be discussed separately below. There is also a specific need for specially trained individuals to administer and interpret the test.

\section{Stimulus Delivery Software and Hardware}

The specialized software required for performing the study is known as stimulus delivery software. This software handles several tasks that are not part of standard MRI studies. Specifically, the software must do three things: (i) synchronize with the MRI scanner software to initiate the proper pulse sequences to be performed by the scanner at the appropriate time, (ii) provide the appropriate stimulus to the subject to activate the brain area of interest at the proper time, and (iii) record any associated data such as feedback from response devices at the appropriate times. To perform these tasks, there are many solutions, offered by both the original equipment manufacturers (OEMs) as well as by third parties.

The ability to synchronize with the native scanner software to perform the appropriate pulse sequence is central to the fMRI experiment. The synchronization is critical because precise knowledge of the task timing relative to image acquisition is required to tease out the small signal differences between task and control conditions. When utilizing OEM stimulus software, it may reside on the scanner console itself. In contrast, when using third party stimulus software, it typically resides on another computer that is linked to the scanner computer, usually through a specialized hardware synchronization device (figure 3).

There are several different stimulus devices that are available that may need to be powered by the stimulus software. In many instances, visual stimuli are provided to the subject. As such, several different kinds of visual display devices may potentially be used. Typically a 
video projector or special MRI compatible eye goggles are used to display a visual stimulus at appropriate times to the subject (figure 3). More recently, several vendors have developed MRI-compatible high definition liquid crystal display (HD-LCD) monitors. In fact, the development of the HD-LCD monitors has necessitated computer hardware upgrades as older systems do not have the high-definition video output that is capable of supporting the HD-LCD monitors. Alternatively, auditory stimuli are commonly used and delivered through non-magnetic headsets or ear buds, and high quality audio-systems are also available for auditory stimulus presentation,. The third component of the stimulus delivery software is the ability to record behavioral data and subject response data at the proper time point. The types of data recorded can be from a variety of devices, such as button boxes and eye tracking cameras (figure 3 ).

\section{Analysis Software}

Analysis software generates the work-product of the entire process. To be useful, the analysis software must be able to accept both BOLD datasets and high resolution anatomical datasets. In the current day, analysis software will typically accept other types of data including perfusion, DTI and angiographic datasets. In almost all instances, the analysis software packages are run on a post-processing workstation, whether the software has been provided by the OEM or not. The analysis software performs two main tasks: (i) data reduction, and (ii) data display. Software subroutines that are useful for the analysis of each of these datasets frequently include BOLD data, DTI data, and high-resolution anatomical data. It should be noted that the typical fMRI experiment generates thousands of images, and that a separate data transfer protocol from the scanner to the post processing station is usually required. The images then need to be appropriately grouped according to the analytic module and statistically analyzed. Activations are then identified based upon a user defined threshold and displayed as a 3D map that is superimposed upon the anatomical images. Typically, it possible to both modify the data in real time and to cut planes and rotate projections viewed in the $3 \mathrm{D}$ and orthogonal view displays. More advanced systems allow one to display activations from multiple task paradigms simultaneously and toggle them on and off (Figure 4).

For archival purposes, a threshold level is chosen by the user and then orthogonal views are output in digital imaging and communications in medicine (DICOM) format for loading into institutional picture archiving and communication systems (PACS). Surgeons also appreciate the ability to export the processed fMRI data to neuronavigation systems for use intraoperatively, and this function is now frequently offered in commercial packages, though data transfer work-arounds used to be necessary. Given the significant impact that these software packages have in clinical decision making, many vendors have obtained approval by the Food and Drug Administration (FDA) for their clinical software packages.

\section{Scanner Hardware Requirements}

The main hardware requirement obviously is a mid or high-field MRI scanner (1.5-3.0 Tesla (T)). There is improved signal observed at higher magnetic field strengths such that fMRI performed at $3 \mathrm{~T}$ MRI is of significantly higher quality than at $1.5 \mathrm{~T}$. $(25,26)$. Echo planar imaging is typically used for fMRI, and as such, the scanner gradient coils must be capable of rapidly switching gradients. A multichannel head coil will also provide improved signal acquisition over a single channel coil. The scanner should be approved for fMRI use prior to implementing a program, and the pulse sequences should then be assessed according to routine quality control guidelines by the institutional MRI physicist.

Retrofitting of an existing MRI scanner to perform fMRI will require physical modifications to the scanner room. The specific hardware required for fMRI stimulus presentation will 
need to be installed. Devices for visual display include eye-goggles, projectors, or MRI compatible LCD panels; audio devices include headphones or ear buds, as described above. Frequently, optical cables are used to transfer the signals from the control room to the scanner room through a device known as a waveguide. Access to the scanning room via a penetration panel may also be necessary for other instrumentation, such as physiological recording equipment. In addition, appropriate mounts for cameras and LCD panels may need to be installed. Once the system is set up, several test runs with control subjects should be performed, to test all components, and train personnel.

\section{Personnel and Training}

Personnel administering the fMRI exam need specific training to use the fMRI hardware and software, as well as on methodological issues related to the functional tasks. In many cases the exams will be performed by technologists, and often the equipment/software manufacturer will provide on site training. The visual display devices must be set up to demonstrate clear images to the subject that are observed by both eyes and can stimulate all of the visual fields. Therefore, goggles are often adjustable to for the interophthalmic distance and requisite visual corrections as needed for each subject. Similarly, projectors or LCD monitors must be positioned such that the subjects can properly see them. When setting up the audio system, care must be taken to insure that the subjects can adequately hear the presented content independently in each ear while the scanner is running.

Additionally, prior to scanning, the technologist will need to instruct the patient and assist with practicing the behavioral task paradigms that will be run. This is crucial to assure that the tasks are performed correctly, so that the functions of interest can be assessed. Patients that are aphasic or have motor deficits may require additional coaching. Ensuring patient comfort and reducing head motion with appropriate padding are paramount, as both factors can affect task performance. Task performance should also be monitored during the scanning session to ensure the task paradigms are followed. After the scan, the data will need to be analyzed by the technologist or additional trained personnel.

The American College of Radiology in collaboration with the American Society of Neuroradiology published guidelines for performing fMRI studies in 2007. In these guidelines, the physician supervising and interpreting fMRI is tasked with being clinically informed about the patient and understanding the "specific questions to be answered prior to the procedure in order to plan and perform it safely and effectively." The physician should also have experience or formal training in the performance of fMRI.

As with any MRI study, the supervising physician must understand indications, risks, and benefits of the examination, as well as the alternative imaging procedures such as a Wada test. Risk assessment involves knowledge of patient factors, including the presence of a pacemaker or other medical device that is potentially hazardous in the MR environment. An understanding of the hazards of MRI contrast encompassing both allergies and the potential of nephrogenic systemic fibrosis in the setting of significant renal impairment is critical if contrast administration is being considered.

The physician interpreting the study should be familiar with the patient's clinical presentation, relevant prior history, and imaging studies. Obviously, the physician performing the fMRI interpretation must also have appropriate knowledge and understanding of the anatomy and pathophysiology in order to render a meaningful interpretation. Experience with fMRI paradigm design, selection, administration and validation is also critical to rendering a quality interpretation. Rigorous quality assessment of every study should take into account factors such as patient compliance with the protocol and patient motion. Confounding issues such as magnetic susceptibility artifact at the 
skullbase or due to the presence of blood-products or metal is essential to performing high quality interpretation. Finally the interpreting physician must understand the BOLD effect and potential sources of neurovascular uncoupling that could cause false negative activations.

\section{CPT Codes}

In the Current Procedural Terminology (CPT) code book in 2007, three new CPT codes were added for functional MRI. (Table 1) The codes can be separated into two main categories: (i) simple paradigms that are performed by a technologist (70554), and (ii) complex paradigms that are administered by a physician or neuropsychologist $(70555+$ 96020). One example of the 70554 code would be simple motor paradigms performed by a technologist without input from a physician to map motor activations. When using the second code, there are many specific criteria that must be met including the need to perform at least two fMRI paradigms with one of the tests being designed to identify higher cognitive function running the gamut from memory and attention tasks to language to executive functioning. Moreover, the physician or psychologist is expected to select the test, demonstrate the test to the subject, administer the test, interpret the results and consult with the referring physician. After this is performed, the 70555 code is billed to report the fMRI portion of the study and 96020 is used to report on the neurocognitive testing. It should be noted that standard neurocognitive testing should not be performed on the same day as functional MRI. Similarly, it is the belief of the American Medical Association, which manages the CPT coding system, that standard MRI is usually not performed on the same day as the fMRI study. If such a study is to be performed on the same day as the fMRI, a separate order is required for each study and a special modifier code is used to demonstrate that MRI brain evaluation beyond the fMRI was also performed.

As with most MRI examinations, many third-party payers require that the site performing the fMRI be accredited. The main accrediting bodies in the United States include the American College of Radiology (ACR), Joint Commission on Accreditation of Healthcare Organizations (JCAHO), Accreditation Association for Ambulatory Health Care (AAAHC/ Accreditation Association) and the Intersocietal Commission for the Accreditation of Magnetic Resonance Laboratories (ICAMRL). Although varying by agency, the accreditation process is comprehensive. For example, the ACR requires that sites submit deidentified images obtained from actual patient studies for quality evaluation by central readers. In addition, there are specified phantom studies that also need to be submitted.

\section{Position of Professional Societies}

Several imaging-based professional societies have adopted positions in support of the development of clinical fMRI programs. These are summarized below. Currently, the American Association of Neurological Surgeons (AANS) and the Congress of Neurological Surgeons (CNS) do not have any official policy, while the American Academy of Neurology (AAN) and the American Society of Functional Neuroradiology are presently conducting systematic reviews of the literature and developing clinical fMRI guidelines.

\section{Radiological Society of North America (RSNA) Position}

According to the RSNA (2007), fMRI is becoming the diagnostic method of choice for learning how a normal, diseased or injured brain is working, as well as for assessing the potential risks of surgery or other invasive treatments of the brain. Physicians perform fMRI to:

- examine the anatomy of the brain. 
- determine precisely which part of the brain is handling critical functions such as thought, speech, movement and sensation, which is called brain mapping.

- help assess the effects of stroke, trauma or degenerative disease (such as Alzheimer's) on brain function.

- monitor the growth and function of brain tumors.

- guide the planning of surgery, radiation therapy, or other surgical treatments for the brain.

\section{American College of Radiology (ACR) Position}

In the October 2007 ACR published a new Practice Guideline "for the Performance of Functional Magnetic Resonance Imaging of the Brain (fMRI)" October 2007. The ACR states that BOLD fMRI is an appropriate method for evaluation of eloquent cortex in relation to focal brain lesions. Typically, either neoplasm or vascular malformation is the suspected lesion.

Primary indications for fMRI include:

\section{A. Assessment of Intracranial Tumoral Disease}

1. Presurgical planning, Assessment of eloquent cortex (e.g., language, sensory motor, visual) in relation to a tumor.

2. Surgical planning (biopsy or resection), Use of fMRI data for surgical guidance or resection procedure.

3. Therapeutic follow-up, Evaluation of preserved eloquent cortex.

B. Assessment of Language Functions for Epilepsy Surgery

In fact this support by professional organizations combined with the wealth of developing literature led to CMS approving CPT codes for fMRI based upon clinical indications summarized above.

\section{Summary}

The growing body of evidence demonstrating the utility of fMRI as a means for presurgical evaluation led to the development of CPT codes for performing clinical fMRI examinations. This has been followed by an increased demand in the number of studies ordered. Structurally, a clinical fMRI service can be established by adding additional hardware and software components to most existing mid- and high-field examinations. There is also a need for specific training for the personnel who will be performing and interpreting the exams.

\section{References}

1. Berger MS. Lesions in functional ("eloquent") cortex and subcortical white matter. Clin Neurosurg. 1994; 41:444-463. [PubMed: 7842620]

2. Claus EB, Horlacher A, Hsu L, Schwartz RB, Dello-Iacono D, Talos F, Jolesz FA, Black PM. Survival rates in patients with low-grade glioma after intraoperative magnetic resonance image guidance. Cancer. 2005; 103:1227-1233. [PubMed: 15690327]

3. Coenen VA, Krings T, Axer H, Weidemann J, Kranzlein H, Hans FJ, Thron A, Gilsbach JM, Rohde $\mathrm{V}$. Intraoperative three-dimensional visualization of the pyramidal tract in a neuronavigation system (PTV) reliably predicts true position of principal motor pathways. Surg Neurol. 2003; 60:381-390. discussion 390. [PubMed: 14572954] 
4. Field AS, Alexander AL. Diffusion tensor imaging in cerebral tumor diagnosis and therapy. Topics Magn Reson Imaging. 2004; 15:315-324.

5. Field AS, Alexander AL, Wu YC, Hasan KM, Witwer B, Badie B. Diffusion tensor eigenvector directional color imaging patterns in the evaluation of cerebral white matter tracts altered by tumor. J Magn Reson Imaging. 2004; 20:555-562. [PubMed: 15390227]

6. Ganslandt O, Fahlbusch R, Nimsky C, Kober H, Moller M, Steinmeier R, Romstock J, Vieth J. Functional neuronavigation with magnetoencephalography: outcome in 50 patients with lesions around the motor cortex. J Neurosurg. 1999; 91:73-79. [PubMed: 10389883]

7. Gralla J, Ganslandt O, Kober H, Buchfelder M, Fahlbusch R, Nimsky C. Image-guided removal of supratentorial cavernomas in critical brain areas: application of neuronavigation and intraoperative magnetic resonance imaging. Minim Invasive Neurosurg. 2003; 46:72-77. [PubMed: 12761675]

8. Haberg A, Kvistad KA, Unsgard G, Haraldseth O. Preoperative blood oxygen level-dependent functional magnetic resonance imaging in patients with primary brain tumors: clinical application and outcome. Neurosurgery. 2004; 54:902-914. discussion 914-905. [PubMed: 15046657]

9. Holodny AI, Schwartz TH, Ollenschleger M, Liu WC, Schulder M. Tumor involvement of the corticospinal tract: diffusion magnetic resonance tractography with intraoperative correlation. $\mathrm{J}$ Neurosurg. 2001; 95:1082. [PubMed: 11765829]

10. Jannin P, Morandi X, Fleig OJ, Le Rumeur E, Toulouse P, Gibaud B, Scarabin JM. Integration of sulcal and functional information for multimodal neuronavigation. J Neurosurg. 2002; 96:713723. [PubMed: 11990812]

11. Krishnan R, Raabe A, Hattingen E, Szelenyi A, Yahya H, Hermann E, Zimmermann M, Seifert V. Functional magnetic resonance imaging-integrated neuronavigation: correlation between lesion-tomotor cortex distance and outcome. Neurosurgery. 2004; 55:904-914. discusssion 914-905. [PubMed: 15458599]

12. Kwong KK, Belliveau JW, Chesler DA, Goldberg IE, Weisskoff RM, Poncelet BP, Kennedy DN, Hoppel BE, Cohen MS, Turner R, et al. Dynamic magnetic resonance imaging of human brain activity during primary sensory stimulation. Proceedings of the National Academy of Sciences of the United States of America. 1992; 89:5675-5679. [PubMed: 1608978]

13. Lehericy S, Duffau H, Cornu P, Capelle L, Pidoux B, Carpentier A, Auliac S, Clemenceau S, Sichez JP, Bitar A, Valery CA, Van Effenterre R, Faillot T, Srour A, Fohanno D, Philippon J, Le Bihan D, Marsault C. Correspondence between functional magnetic resonance imaging somatotopy and individual brain anatomy of the central region: comparison with intraoperative stimulation in patients with brain tumors. J Neurosurg. 2000; 92:589-598. [PubMed: 10761647]

14. Maldjian JA, Schulder M, Liu WC, Mun IK, Hirschorn D, Murthy R, Carmel P, Kalnin A. Intraoperative functional MRI using a real-time neurosurgical navigation system. J Comput Assist Tomogr. 1997; 21:910-912. [PubMed: 9386283]

15. Mori S, Frederiksen K, van Zijl PC, Stieltjes B, Kraut MA, Solaiyappan M, Pomper MG. Brain white matter anatomy of tumor patients evaluated with diffusion tensor imaging. Ann Neurol. 2002; 51:377-380. [PubMed: 11891834]

16. Mueller WM, Yetkin FZ, Hammeke TA, Morris GL 3rd, Swanson SJ, Reichert K, Cox R, Haughton VM. Functional magnetic resonance imaging mapping of the motor cortex in patients with cerebral tumors. Neurosurgery. 1996; 39:515-520. discussion 520-511. [PubMed: 8875481]

17. Nimsky C, Ganslandt O, Kober H, Moller M, Ulmer S, Tomandl B, Fahlbusch R. Integration of functional magnetic resonance imaging supported by magnetoencephalography in functional neuronavigation. Neurosurgery. 1999; 44:1249-1255. discussion 1255-1246. [PubMed: 10371623]

18. O'Shea JP, Whalen S, Branco DM, Petrovich NM, Knierim KE, Golby AJ. Integrated image- and function-guided surgery in eloquent cortex: a technique report. Int J Med Robot. 2006; 2:75-83. [PubMed: 17520616]

19. Ogawa S, Lee TM, Kay AR, Tank DW. Brain magnetic resonance imaging with contrast dependent on blood oxygenation. Proceedings of the National Academy of Sciences of the United States of America. 1990; 87:9868-9872. [PubMed: 2124706]

20. Petrella JR, Shah LM, Harris KM, Friedman AH, George TM, Sampson JH, Pekala JS, Voyvodic JT. Preoperative functional MR imaging localization of language and motor areas: effect on 
therapeutic decision making in patients with potentially resectable brain tumors. Radiology. 2006; 240:793-802. [PubMed: 16857981]

21. Piepmeier J, Christopher S, Spencer D, Byrne T, Kim J, Knisel JP, Lacy J, Tsukerman L, Makuch R. Variations in the natural history and survival of patients with supratentorial low-grade astrocytomas. Neurosurgery. 1996; 38:872-878. discussion 878-879. [PubMed: 8727811]

22. Reithmeier T, Krammer M, Gumprecht H, Gerstner W, Lumenta CB. Neuronavigation combined with electrophysiological monitoring for surgery of lesions in eloquent brain areas in 42 cases: a retrospective comparison of the neurological outcome and the quality of resection with a control group with similar lesions. Minim Invasive Neurosurg. 2003; 46:65-71. [PubMed: 12761674]

23. Roessler K, Donat M, Lanzenberger R, Novak K, Geissler A, Gartus A, Tahamtan AR, Milakara D, Czech T, Barth M, Knosp E, Beisteiner R. Evaluation of preoperative high magnetic field motor functional MRI (3 Tesla) in glioma patients by navigated electrocortical stimulation and postoperative outcome. J Neurol Neurosurg Psychiatry. 2005; 76:1152-1157. [PubMed: 16024896]

24. Roy CS, Sherrington CS. On the Regulation of the Blood-supply of the Brain. J Physiol. 1890; 11:85-158. 117.

25. Soher BJ, Dale BM, Merkle EM. A review of MR physics: 3T versus 1.5T. Magn Reson Imaging Clin N Am. 2007; 15:277-290. v. [PubMed: 17893049]

26. Tieleman A, Vandemaele P, Seurinck R, Deblaere K, Achten E. Comparison between functional magnetic resonance imaging at 1.5 and 3 Tesla: effect of increased field strength on 4 paradigms used during presurgical work-up. Invest Radiol. 2007; 42:130-138. [PubMed: 17220731]

27. Tummala RP, Chu RM, Liu H, Truwit CL, Hall WA. Application of diffusion tensor imaging to magnetic-resonance-guided brain tumor resection. Pediatr Neurosurg. 2003; 39:39-43. [PubMed: 12784077]

28. Wieshmann UC, Symms MR, Parker GJ, Clark CA, Lemieux L, Barker GJ, Shorvon SD. Diffusion tensor imaging demonstrates deviation of fibres in normal appearing white matter adjacent to a brain tumour. J Neurol Neurosurg Psychiatry. 2000; 68:501-503. [PubMed: 10727488]

29. Witwer BP, Moftakhar R, Hasan KM, Deshmukh P, Haughton V, Field A, Arfanakis K, Noyes J, Moritz CH, Meyerand ME, Rowley HA, Alexander AL, Badie B. Diffusion-tensor imaging of white matter tracts in patients with cerebral neoplasm. J Neurosurg. 2002; 97:568-575. [PubMed: 12296640] 


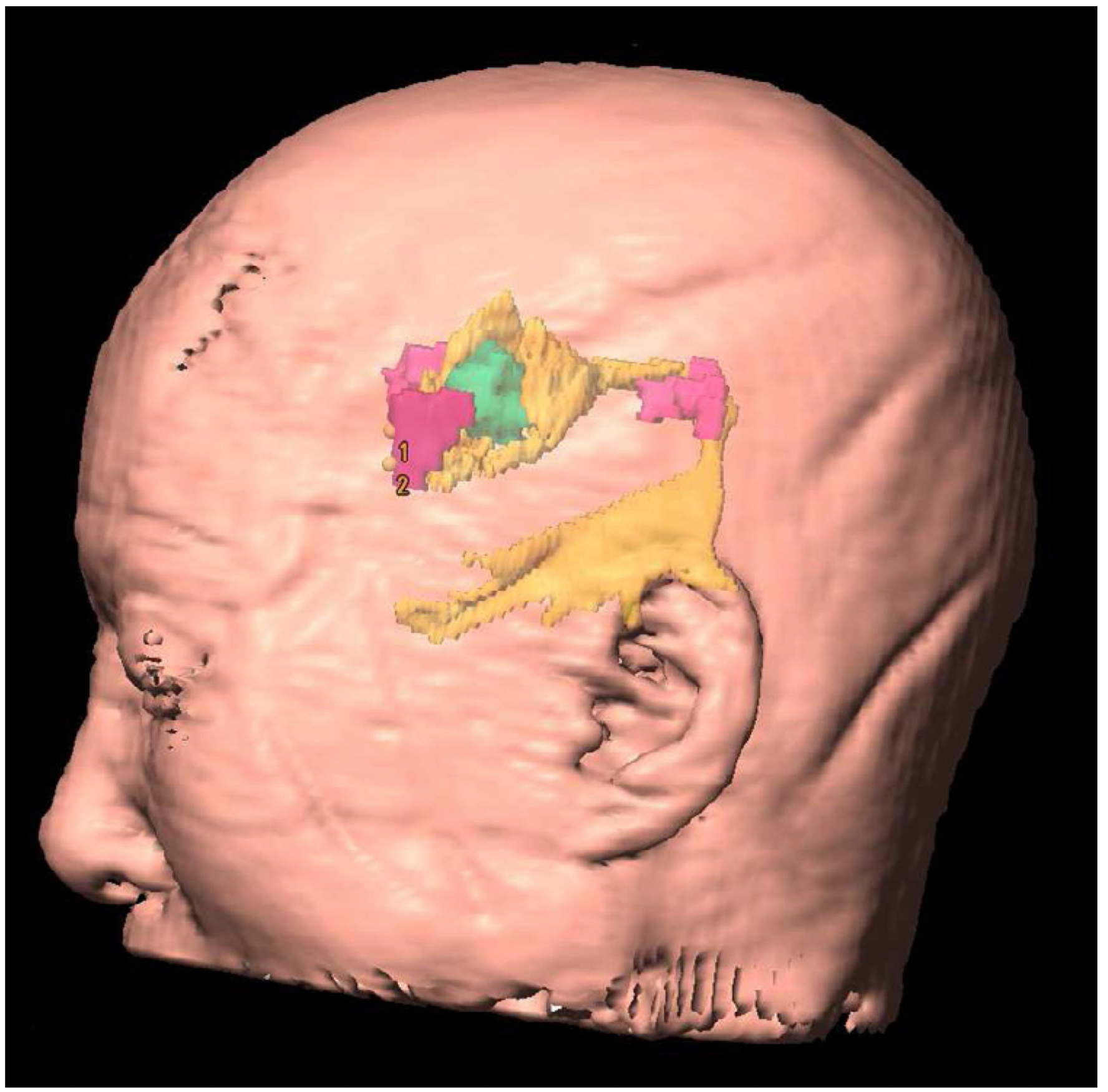

Figure 1.

An Example of intra-operative display of BOLD data. The tumor volume is segmented in green, language task BOLD activations are displayed in pink, and DTI based fiber tractography is displayed in yellow. 


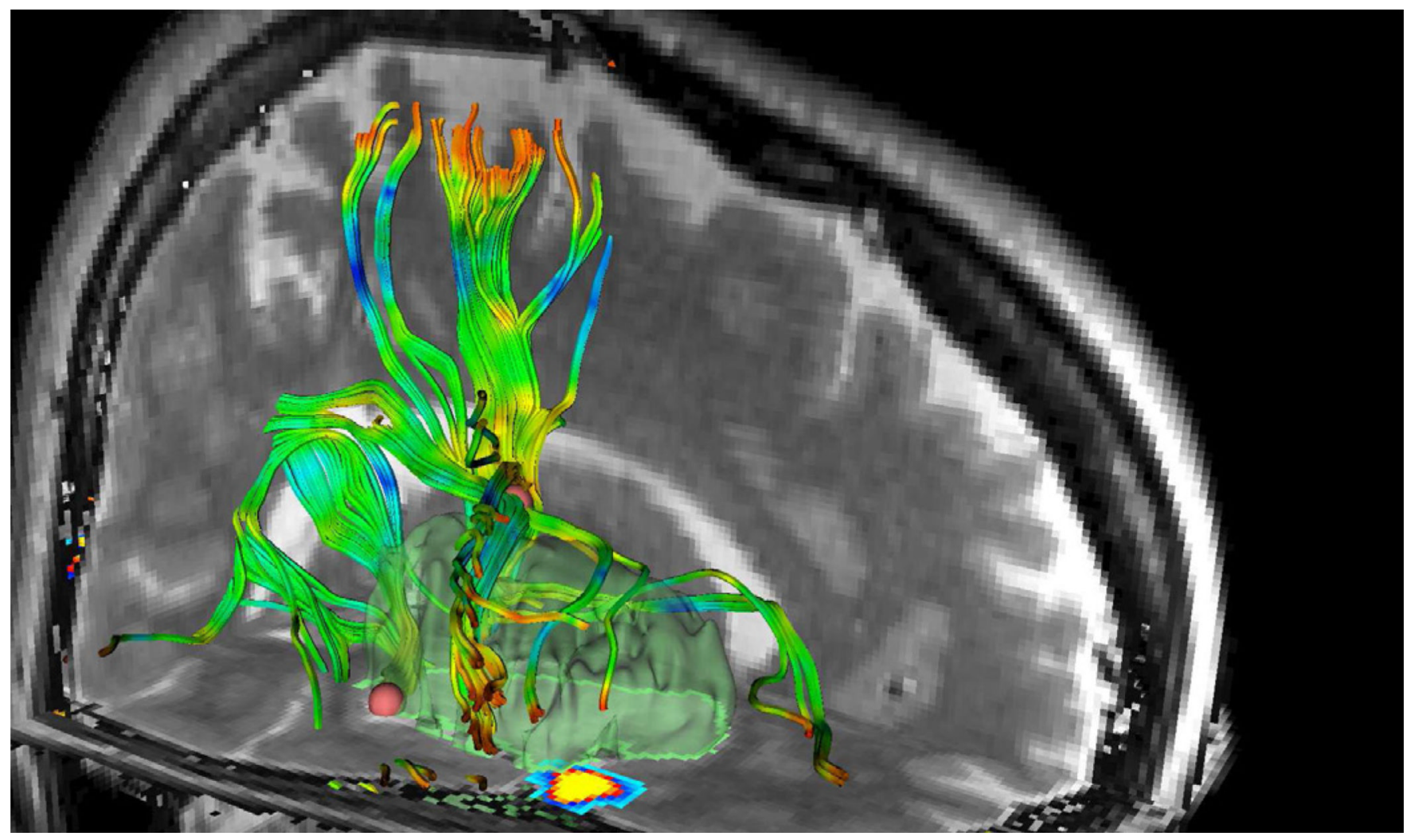

Figure 2.

DTI tractography (tubes) displayed with the segmented tumor volume (transparent green), and a proximal fMRI activation. The red sphere is the tract seed point. 

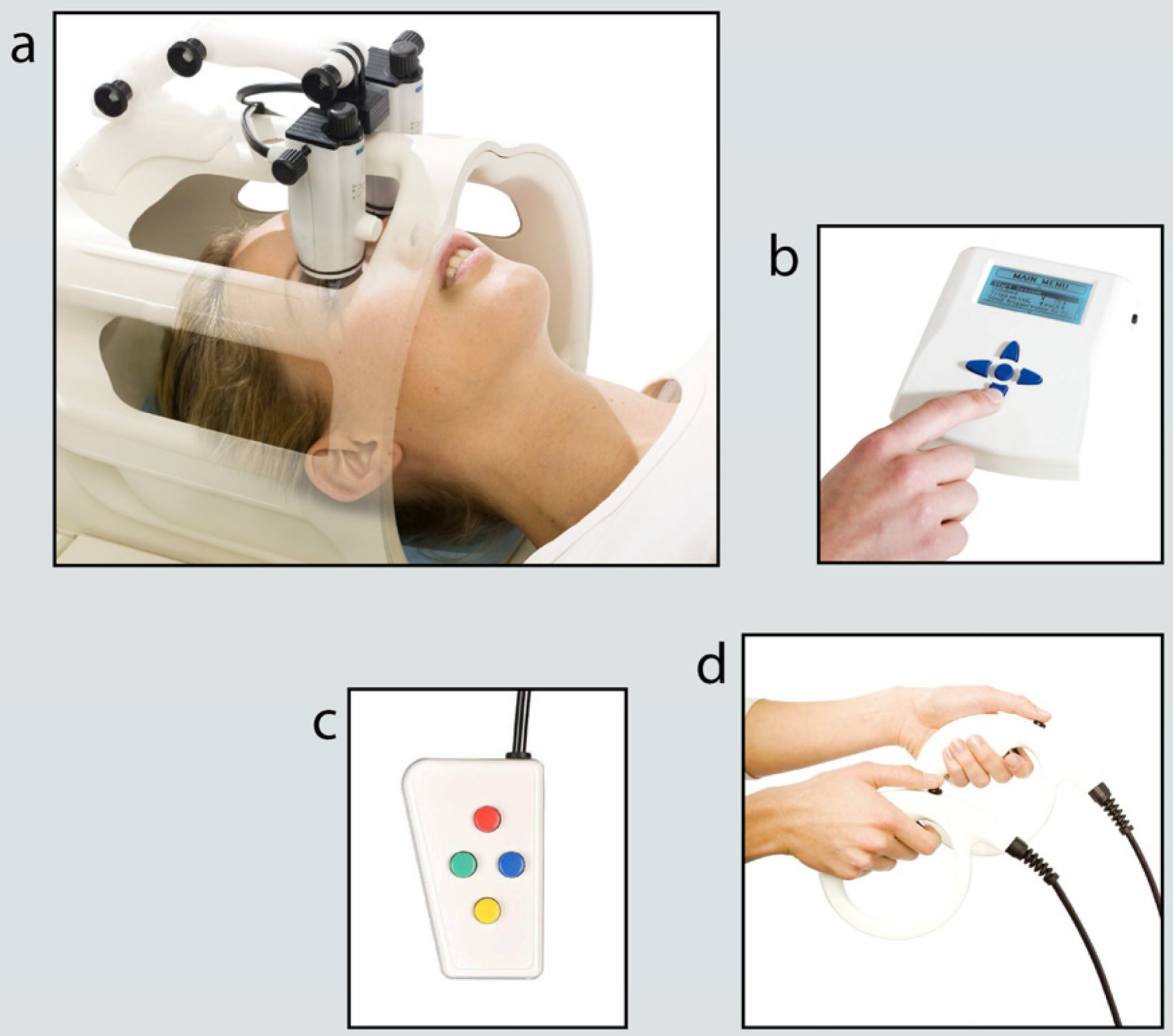

Figure 3.

Examples hardware used to perform fMRI. A goggle system used to display stimuli during an exam (a), a synchronization box used to synch the paradigm and scanner (b), and input devices for response recording (c) and (d). 


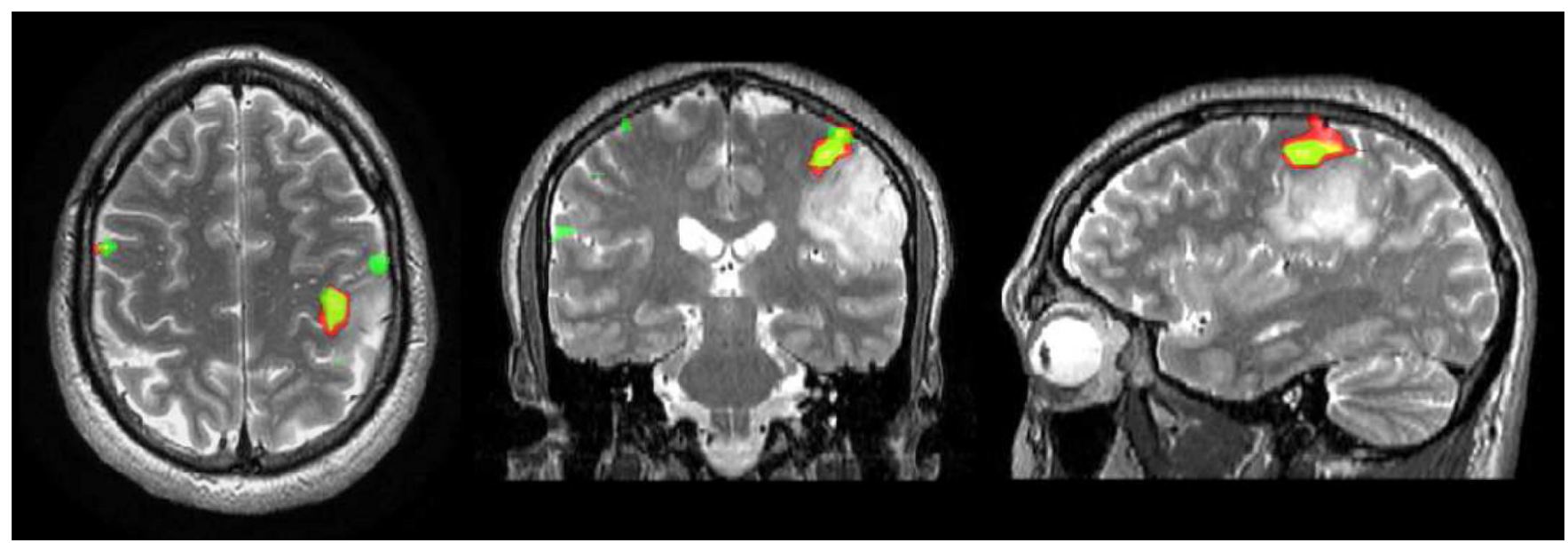

Figure 4.

An example of thresholded data used for presurgical planning from both a hand clenching task (red, $\mathrm{t}=5.31$ ) and a finger tapping task (green, $\mathrm{t}=7.35$ ). 
Table 1

Summary of the current procedural terminology codes (CPT codes) for fMRI.

\begin{tabular}{|l|l|}
\hline CPT Code & Description \\
\hline 70554 & $\begin{array}{l}\text { Functional MRI selected and performed by a technologist. } \\
\text { Do not report with CPT 96020, or CPT 70555. }\end{array}$ \\
\hline 70555 & $\begin{array}{l}\text { Complex paradigms for fMRI selected and performed by a physician or psychologist, involving neurofunctional testing. } \\
\text { Report with CPT 96020. }\end{array}$ \\
\hline 96020 & $\begin{array}{l}\text { Neurofunctional testing by physician or psychologist, with review of results and report. } \\
\text { Report with CPT 70555. }\end{array}$ \\
\hline
\end{tabular}

